\title{
Knowledge Management System Model Development for Higher Technical Vocational Education
}

\author{
Eduardus Dimas Arya Sadewa, Romadhani Ardi, and Amalia Suzianti
}

\begin{abstract}
Knowledge management extensively applied in enterprise because it significantly effect on enterprise effectiveness and innovation strategy. In order to create professionalism in form of competencies, education institution also implemented knowledge management concept. Education institution as a knowledge business is a suitable form for a knowledge management development, especially in vocational education. With practical approach methods and strong industrial relationship in order to improve their student skills, vocational education has plenty of knowledge sources to create knowledge as institutions intangible asset. From prior study, knowledge management system in vocational education is unstructured. This study focus in developed a KMS model in higher vocational education institution. The model showed that relation between organization environment and KM infrastructure effect on knowledge flow. KM assessment level and knowledge flow configured KM strategy to establish KM roadmap. The KMS model test on Polman Astra institution.
\end{abstract}

Keywords-Knowledge management, higher vocational education, knowledge management model.

\section{INTRODUCTION}

Knowledge management (KM) is a process to collecting, managing, sharing knowledge which collected in a period of time for developing and elevated organization's competitiveness. Knowledge management becomes alternative for organization to develop their core competencies [1]. Implementations of KM in business field and educational institution have different goal. The main goal of implementing $\mathrm{KM}$ in educational institution is to create professionalism in form of competencies and personal identity among graduates [2]. Education institusion should be a best practices of advancing their teaching and learning by involving learning process, knowledge creation, and knowledge dissemination inside their process [3]. Vocational education is one of the education model that created to fullfil the industrial needs of skilled and competence worker. Several approches in vocational education to improve their knowledge and skill are production based learning [4][5] and competence based learning [6]. These approches are valuable for gathered and developed the organizations knowledge. Early stages

Eduardus Dimas Arya Sadewa, Romadhani Ardi, and Amalia Suzianti are with Department of Industrial Engineering, Universitas Indonesia, Depok, 16424, Indonesia. E-mail: arya.sadewa@gmail.com. research of implementation $\mathrm{KM}$ in technical vocational education and training (TVET) are focuses on information technology, Culture, communication planning organization process; and strengthening of human resources [7].

This research will focus on developing a structured knowledge management system model in Technical Vocational Education and Training (TVET) so the process of identifying, capturing and creating knowledge can be done in higher vocational education, transferring and reusing knowledge also can help improve institutional competency.

\section{LITERATURE REVIEW}

Organizations contribute to organizing existing information into knowledge to be developed into organizational knowledge. It needs strategy to design the development and implementation of KM [8].

In the view of KM contingency, to decide a knowledge management solution, there needs to be several alternative steps and then selecting appropriate steps to enable knowledge management to succeed [1]. As shown in figure 1 , the first step of $\mathrm{KM}$ contingency is to determine the appropriate process of $\mathrm{KM}$ that support by the $\mathrm{KM}$ mechanism and technology. KM infrastructure should support KM mechanism and technology that will affect KM system. KM system will support KM processes.

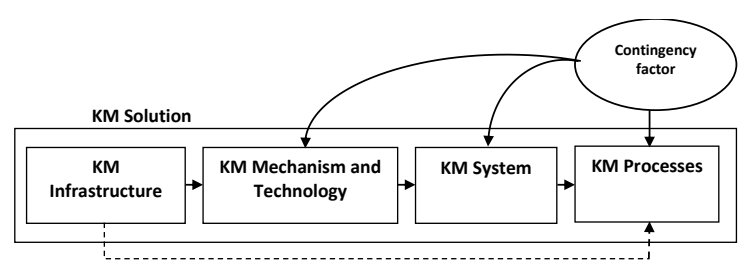

Figure 1. KM contingency.

Infrastructure is foundation for $\mathrm{KM}$ in the organization. The foundation consists of five components [1]; 1) Organization culture, 2) Organization structure, 3) Information technology, 4) Common knowledge, 5) Physical environment.

In order to construct a KM, Calabrese (2000) in his study was examed the importance of one KM pillar over the other and the correlation between pillars and ranking it. The result are leader are needed in determining the direction and then arranges the implementation, creating organizational 
structures and rules that can accept the culture of knowledge sharing and facilitated with technology and networking tools to be able to reach learning institutions. A guide is required in order to analyze needs and design solutions by gap, opportunity and risk to identify and appropriately use knowledge in the company's daily activities [9].

A strategy, design, development and implementation of knowledge management initiation program is needed in applying KM to an institution which is all set forth in the form of knowledge management roadmap [8]. Stages are divided into 4 phases as follows; 1) Infrastructure evaluation, 2) Analysis, design and development of KM System, 3) System of task deployment, 4) Performance evaluation

Assessment is made at the beginning of the $\mathrm{KM}$ program to identify strengths and opportunities for development and focus on identified gaps from the assessment results. APO Knowledge management assessment tools are descriptions of questionnaires used to assist organizations in conducting preliminary assessments of the KM readiness applications. Seven categories corresponding to the elements present in the KM framework for assessment; 1) KM Leadership, 2) Process, 3) People, 4) Technology, 5) Knowledge process, 6) Learning and innovation, 7) KM outcomes.

\section{ELEMENTS OF KM MODEL FOR VOCATIONS EDUCATION.}

Environmental factors, both internal and external, play a role in determining the design of knowledge management application plans in higher technical vocation education institutions. There are several things that have an effect on environmental factors in higher technical vocational education;

1. Understand the organization's vision, mission, goals and strategic direction to identify core competencies to be built by the organization [10].

2. Cooperation with other institutions is needed so that the vocational institution can fulfill its role in developed the needs of a competent professional workforce. For institutions of higher technical vocational education, industrial societies can help identify appropriate curriculum needs [5][6].

3. The Government plays an important role as regulators and the determination of the strategic direction of the country. Changes and development of institutions must comply with existing regulations [5][11].

Infrastructure component for knowledge management activities of vocational education institutions consist of;

1. Organizational culture that can facilitate knowledge sharing for all levels of employees and encourage employees to issue their ideas [7].

2. Organizational structure should accommodate three higher education institutions duty where education institutions should be able to carry out teaching and training, community service and research for engineering and design [6].

3. Physical environment, building design, inter-section location, meeting room is a supportive part in the application of knowledge management in educational institutions. Collaborative physical space is one of the methods that can support sharing process and creating knowledge [10], because the activities of teaching and learning process in vocational education institutions are mostly done in workshop area [5].

4. Information technology system infrastructure is not sufficient to support the application of knowledge management systems within the organization, there needs to be measurement of technology acceptance from users so that the system built can effectively support the knowledge management system [12].

5. Each organization has a specific language vocabulary in its activities, a knowledge management scheme, a grouping of individual abilities within an organization where all derive from experiences.

The pattern scheme of the knowledge management system model for vocational education can be seen in appendices 1 .

\section{IMPLEMENTATION MODEL: CASE STUDY AT POLITEKNIK MANUFAKTUR ASTRA (POLMAN ASTRA)}

Politeknik Manufaktur Astra (Polman Astra) is a vocational education institution that prepares its students to participate as a skilled worker in the manufacturing industry [13]. Several elements of Polman Astra are reviewed to develop a Polman astra knowledge management system

\section{A. Internal factors}

Polman Astra vision is "Being the best Polytechnic in Indonesia and able to compete in Southeast Asia" and the vision described in the form of mission as institutional consequence to make it happen.

Polman Astra's mission is:

1. Produce ready-to-use Diploma degree graduates in automotive and natural resources-related fields including QCDI quality mindset (Quality, Cost, Delivery, and Innovation), discipline and have learning abilities to meet the demands of global industry development.

2. Creating a professional academic environment to cultivate the competence and potential of all member of Polman Astra Institution

Polman Astra strategic achievement plan discussed in internal discussion about the conformity of National Standards of Higher Education according to PerMenristekdikti Nomor 44 tahun 2015 (ministry of research, technology and higher educational directorate regulation) about the suitability of achievement with the national standards of universities and gaps that occur today. From the analysis of the criteria of higher education standards, it is formed into Polman Astra's strategy on the 
improvement and development of education characterized by .Astra Catur Dharma (four Astra duty); the development of education management system; improving the quality of prospective students, processes and graduates; empowering resources in technology development and learning process; and develop a learning quality refer to international education as well as research development.

\section{B. External factors}

External factors affecting Polman Astra are government regulation in the development of national higher education system as stipulated in Peraturan Presiden no. 8 tahun 2012 (presidential regulation) on KKNI (Indonesian National Qualification Framework) and also cooperation with industry as part of service to society. At the level of diploma degree, the level of KKNI in the world of work is at level 5 which shows the technician or analyst with a qualification area:

1. Be able to complete wide-ranging work, choose appropriate methods from various options that have been or have not been standardized by analyzing the data and able to demonstrate performance with quality and quantity measurable

2. Mastering the theoretical concepts of a particular field of knowledge in general and able to formulate the solution of procedural problems.

3. Able to manage the working group and prepare a comprehensive written report.

4. Responsible for the work itself and can be given responsibility for the achievement of group work results

Industrial cooperation is one of the factors that can help Polman Astra to develop projects that can provide mutual benefits for both parties in the field of academic as well as in the field of research. The cooperation is done with the industry in accordance with the study program run in Polman Astra. Through this cooperation, the industry can influence the work patterns and teaching systems in Polman Astra close to real conditions in the industry.

\section{Polman Astra infrastructure consists of}

1. Organizational structure; Polman Astra is managed by the director who is in the execution process assisted by the vice director I in the fields of academic, student affairs, and industrial cooperation, Vice Director II in the fields of finance, public service and human resources, Vice Director III on the field of teaching practice and service industry, LP2M ( Institute for Research and Community Service), LP3T (Institute for Product Development and Application of Technology), BPM (Quality Assurance Agency).

2. The organizational culture of Polman Astra; The mission of Polman Astra is to form a professional workforce who has a mindset on QCDI (Quality, Cost, Delivery, Innovation), discipline and willingness to learn. Duration of practice is equated with the industrial working hours, practice assessment emphasis on the quality of the module or the product, accuracy and speed, and the method used, the opportunity for students innovation by get involved them in the quality improvement team guided by the instructor for improvement in the work area and will the results will be competed with other innovation. For employees and teachers, they required to write key performance indicator (KPI) from job description to measure achievement of their job and improvement that they developed. Problem solving on improvement process is done by brainstorming in the area where the problem occurs. The process of the problem solving is written in one sheet report from problem identification to how it solved.

3. Information technology infrastructure; Initial research was conducted to measure the users readiness of $\mathrm{KM}$ system applications that will be developed in Polman Astra in order to gathered information about the capabilities and habits of prospective users on information communication technology. The analysis results obtained basic ability of internet usage is high enough and tendency of user use social media application daily. Users dominantly used Internet access using mobile devices and tablets instead of using personal computers (PCs) or notebooks.

4. The physical facilities of Polman Astra; Polman Astra completes physical infrastructure in the form of offices for administrative activities, lecture hall, meeting room and discussion, lecturer workspace, laboratory and library. Due to the limited facilities and conditions of the process at the time, mentoring, brainstorming, discussion and problem-solving activities were mostly done in the workshop area

\section{Learning system}

Polman Astra as a vocational higher education institution that implements a dual system which is more focused on systematic practice learning by $65 \%$ and supported by applicative theory of $35 \%$.

Polman Astra has a production section that supports technical competence development activities and competencies management as well as industrial projects. There are experience of workmanship, problem solving and documentation, the process of brainstorming and documentation, but not yet integrated so that knowledge is still left in their respective sections. This makes the flow of knowledge in Polman Astra unstructured and has not been able to support knowledge transfer activities and the reusing knowledge for the creation of new knowledge.

\section{E. Polman Astra Knowledge Management Assessment Level}

The first step to identifying the strengths and opportunities for knowledge management development is to assess the maturity of knowledge management within the institution.

1. Demographics of respondents. Respondents are both internal teachers of practice and theory with a total of 46 respondents. Respondents are grouped into; Age to see 
the comparison between senior and junior employees, dominated by employees aged $20-30$ by $42 \%$ and those aged $41-50$ by $39 \%$ so that knowledge transfer between them is required; Education to see the intellectual level, $42 \%$ have a bachelor degree. The level of education can provide an overview of the capabilities of the employee in the implementation of knowledge management programs; and workgroups to see the functions and responsibilities within the institution, of which $51 \%$ are group 4 where they have organizational structural and operational responsibilities.

2. Average value of the validity test's data shows 0.683 which mean quite correlated and average reliability test value show the number 0.745 which means quite reliable.

3. On the radar chart as shown in Figure 2 can be seen there are two conditions of the expected value and the measured value of the current conditions. The expected value is measured from respondents with more tasks and responsibilities than others and those with managerial functions in Polman Astra. The current state of the condition is given by almost all teachers at all levels.

4. In the category of technology in the current condition value is the highest value of 3.31 and knowledge process is the lowest value of 2.54 .

5. The total point of knowledge management maturity level in Polman Astra is 117.59. Based on points obtained, Polman Astra is at the level of Initiation where Polman Astra began to recognized the need for KM implementation within the institution.

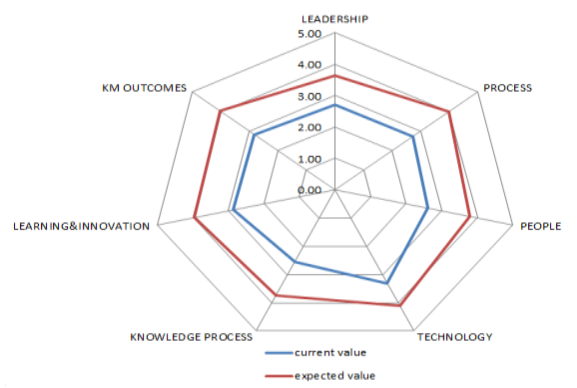

Figure 2. Polman Astra assessment level radar chart.

6. Generally the result of this strength and opportunity matrix is the need for a structured program to maintain and develop the knowledge of Polman Astra accompanied by regular knowledge sharing among sections in order to get innovative ideas with support from institutions through incentives. In order for the process to be better there should be an evaluation and improvement of the standard operating operations performed by the parties concerned, accompanied by input from senior staff or those who will retire. It needs a storage of results from the work process in the form of ideas, developments and evaluations that can be accessed again so that innovation becomes a culture and Polman Astra becomes a learning organization.

\section{DEVELOPMENT OF KNOWLEDGE MANAGEMENT STRATEGY IN POLMAN ASTRA}

Data analysis supporting elements of knowledge management strategy concept in Polman Astra:

A. Internal and external environmental factors Polman Astra

1. Development of competencies adapts to government qualifications.

2. Cooperation with industry helps capture the knowledge through industry internships, knowledge sharing and knowledge development through collaborative projects.

3. The knowledge in the procedures and rules can be used to develop organizational culture and declarative knowledge approaches can be used on product development and teaching systems.

\section{B. Infrastructure}

1. Organizational structure;

a. Knowledge is stored in each part because it does not have an integrated storage system.

b. There are teams that control the activities undertaken.

c. There are knowledge artifacts in the form of the process being run as well as the team that performs and stores the knowledge

2. Organizational culture; Already using brainstorming mechanisms in the process of knowledge sharing and knowledge development

3. Physical facilities; Knowledge embedded to the process is captured and developed in workspace area, need a good storage system so that knowledge is not spread.

4. Information technology; Need an information technology system that supports knowledge sharing and storing process.

C. Learning system

1. The process for capturing and sharing of knowledge can be done in teaching and learning activities and activities in industrial environments.

2. There needs to integrated all of the knowledge storages and access able for other team in order to reuse the knowledge

3. The concept of knowledge flow in Polman Astra can be seen in Figure 3.

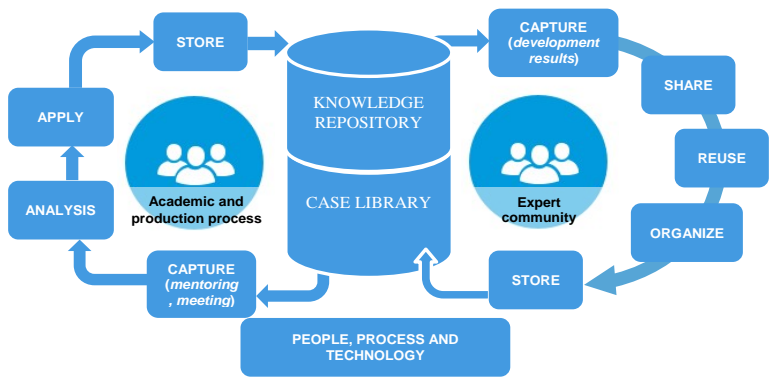

Figure 3. Polman Astra knowledge flow concept. 


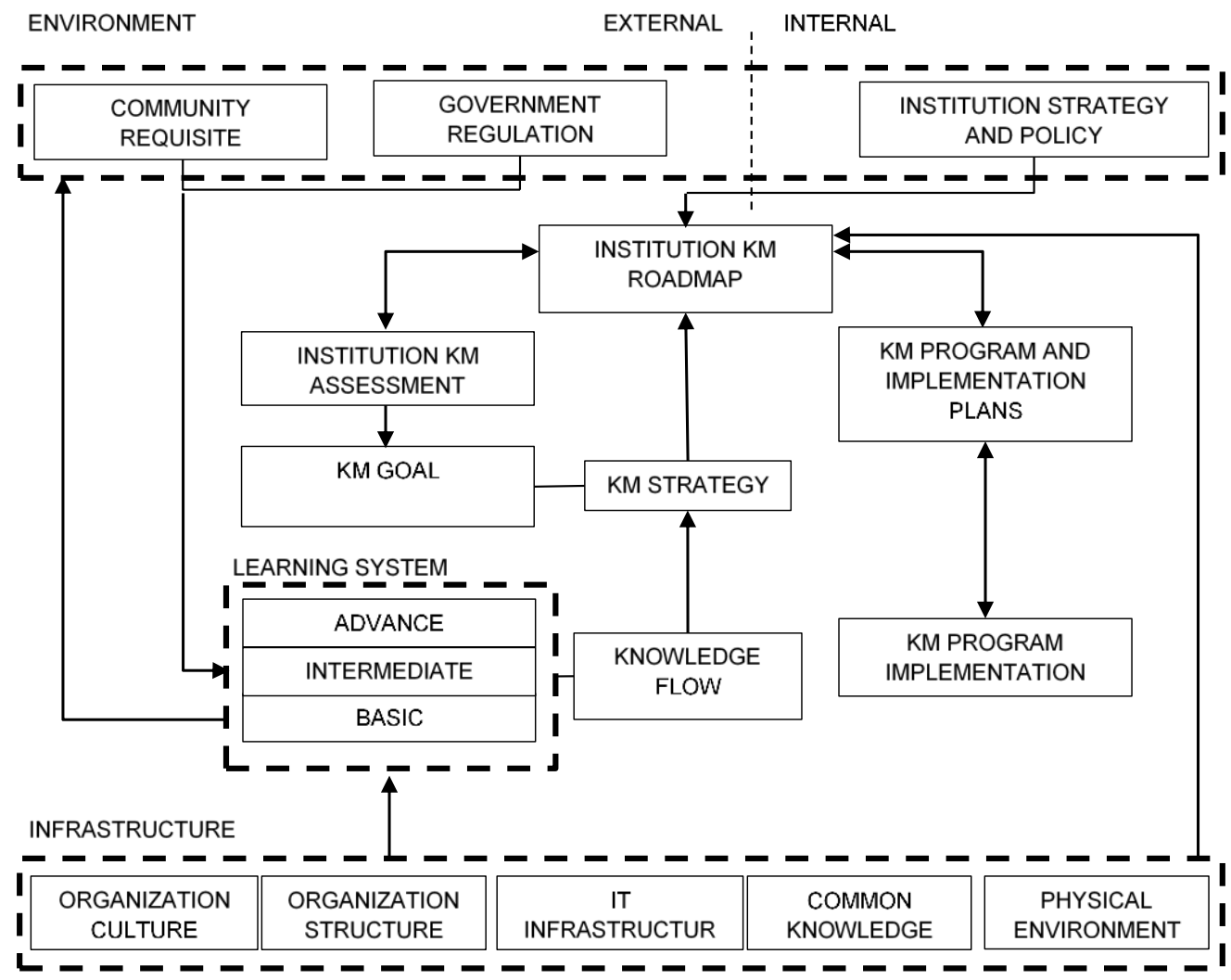

Figure 4. KM Model for high vocational education.

\begin{tabular}{|c|c|c|}
\hline & \multirow{3}{*}{$\begin{array}{l}\text { Strategy and } \\
\text { knowledge } \\
\text { relation }\end{array}$} & $\begin{array}{l}\text { Polman Astra Value } \\
\text { Polman Astra becomes Learning organization }\end{array}$ \\
\hline $\begin{array}{l}\text { Polman Astra must know } \\
\text { - Classification of knowledge to facilitate storage. } \\
\text { - Preparation of physical and technology } \\
\text { infrastructure } \\
\text { - Part of the organizational structure that can assist } \\
\text { in the KM implementation } \\
\text { - Appropriate social media-based form } \\
\text { applications }\end{array}$ & & $\begin{array}{l}\text { Polman Astra must do } \\
\text { - Case based reasoning } \\
\text { - Collaborative physical workspace } \\
\text { - Create KM technology applications in social } \\
\text { media form. } \\
\text { - Introduction of KM system to all Polman } \\
\text { Astra members. }\end{array}$ \\
\hline I Knowledge gap & & Strategy gap \\
\hline $\begin{array}{l}\text { Polman Astra know } \\
\text { - Activities sharing and finding knowledge in the } \\
\text { work area } \\
\text { - Social media forms can be applied to help } \\
\text { capturing and developing knowledge process } \\
\text { - There is no storage institutional knowledge } \\
\text { integration } \\
\text { - Need structured activities to build KM system. }\end{array}$ & $\begin{array}{l}\text { Knowledge and } \\
\text { strategy relation }\end{array}$ & $\begin{array}{l}\text { Polman Astra can do } \\
\text { - Utilization of areas to capture, share and } \\
\text { discover new knowledge } \\
\text { - Creating knowledge management applications } \\
\text { based on social media } \\
\text { - Develop a repository model for knowledge } \\
\text { classification } \\
\text { - Emerge awareness of KM among employees } \\
\text { and students }\end{array}$ \\
\hline
\end{tabular}

Figure 5. Polman Astra KM strategy. 
International Conference on Engineering, Advance Science and Industrial Application (ICETESIA) 2018 September 6-7 2018, Institut Teknologi Sepuluh Nopember, Surabaya, Indonesia

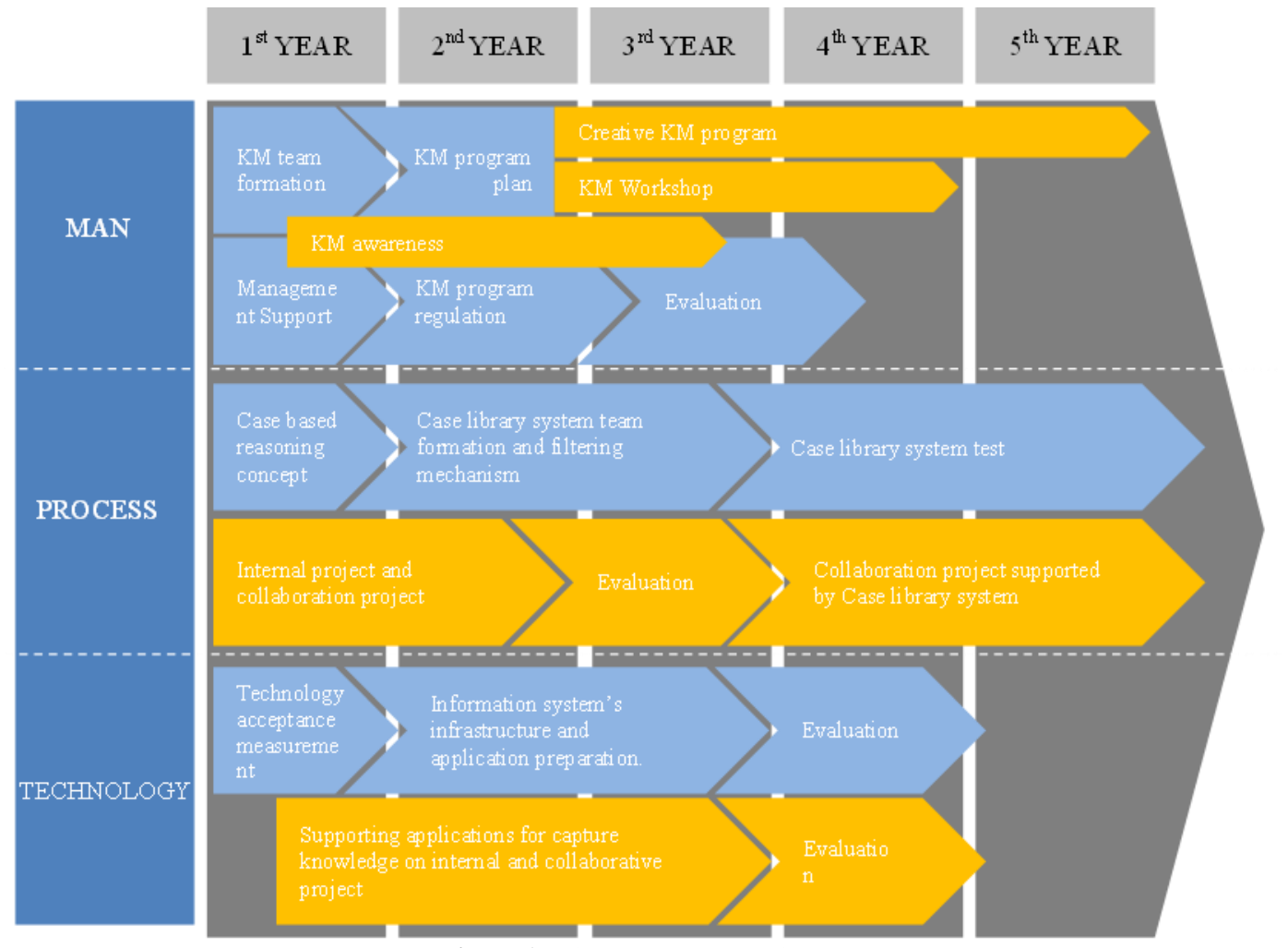

Figure 6. Polman Astra KM roadmap.

\section{KM Assessment level}

1. Need regular knowledge sharing

2. Incentives to innovative ideas

3. Need a knowledge capture mechanism from senior employees

4. There needs to develop a knowledge repository

\section{E. Knowledge management solution at Polman Astra:}

1. Solutions in the form of a routine knowledge approach are used where the knowledge embedded in the procedures can be used to develop organizational culture and declarative knowledge approaches such as product development and the development of teaching systems.

2. The process of capturing the knowledge undertaken in Polman Astra today is through sub processes:

3. Internalization with the KM mechanism in form of lecturing process, mentoring in practice, mentoring for new employees, industry internships both for students and teachers.

4. Externalization with the KM mechanism in form of apprenticeship report, project progress report, log book, minute meeting.

5. While the process of sharing knowledge in Polman Astra done through sub process:

6. Socialization with KM mechanisms in the form of joint project implementation between departments.

7. Exchange with a KM mechanism in the form of document exchange between departments.
8. Characteristics of knowledge undertaken at Polman Astra leads to procedural knowledge, which leads to the sequence of steps and activities in the "know how" direction and in the development process in the knowhow direction to obtain the desired results through the routine and direction sub processes.

9. Infrastructure, especially technology, has a main role in the formation of knowledge management concept of Polman Astra. The social media platform using smart phone devices is an acceptable form and it expected to be applied to support KMS in Polman Astra. The physical condition of Polman Astra supports for application of collaborative physical workspace mechanism in knowledge sharing process.

The scheme of knowledge management development strategy in Polman astra can be seen in appendices 2.

\section{POLMAN ASTRA KM ROADMAP}

After creating a strategy for KM development in Polman astra, the next step is to plan the stages of KM application based on human, process and technology. Stages will be implemented for five years and the achievement will be assessed every year. The road map scheme for knowledge management in Polman Astra can be seen in appendices 3.

\section{CONCLUSION}

To develop a structured KM model for vocational higher education, important factors such as internal and external 
organizational factors, organizational knowledge management infrastructure readiness, learning systems and the flow of existing knowledge within the organization that must be integrated. In addition, it is necessary to measure the current level of organizational knowledge management to know the strengths that support the KM program and the deficiencies that must be improved in the next program.

The results of the experimental model of knowledge management in the Polman Astra case study, this model can help mapping the flow of knowledge to determine the KM strategy and developed the institution KM roadmap

The limitation of this research is this KM model was developed for higher education vocational techniques with education characteristics in Indonesia.

For further research will be conducted deeper study on more objective measurement methods on infrastructure such as organizational structure and organizational culture, and development of evaluation methods and $\mathrm{KM}$ application in institutions.

\section{REFERENCES}

[1] I. Becerra-Fernandez, A. J. González, and R. Sabherwal, Knowledge management: challenges, solutions, and technologies. Pearson/Prentice Hall, 2004.

[2] V. M. Smokotin, G. I. Petrova, and S. K. Gural, "Theoretical Principles for Knowledge Management in the Research University," Procedia - Soc. Behav. Sci., vol. 154, pp. 229-232, Oct. 2014.
[3] B. Demchig, "Knowledge Management Capability Level Assessment of the Higher Education Institutions: Case Study from Mongolia," Procedia - Soc. Behav. Sci., vol. 174, pp. 3633-3640, Feb. 2015

[4] Ganefri and H. Hidayat, "Production based Learning: An Instructional Design Model in the Context of Vocational Education and Training (VET)," Procedia - Soc. Behav. Sci., vol. 204, pp. 206-211, Aug. 2015.

[5] I. P. Ilyas and T. Semiawan, "Production Based Education (PBE): The Future Perspective of Education on Manufacturing Excellent," Procedia - Soc. Behav. Sci., vol. 52, pp. 5-14, 2012.

[6] P. Boahin and W. H. A. Hofman, "Perceived Effects of Competency-Based Training on The Acquisition of Professional Skills," Int. J. Educ. Dev., vol. 36, pp. 81-89, 2014.

[7] H. Symons, "Knowledge management in technical and vocational education and training," in UNESCO Regional Conference, 2001.

[8] A. Tiwana, "The 10 Step Knowledge Management Road Map," in The Knowledge Management Toolkit: Orchestrating It, Strategy, and Knowledge Platforms, 2002, pp. 67-74.

[9] A. Francesco and Calabrese, Creating the Discipline of Knowledge Management. Oxford: Elsevier ButterworthHeinemann, 2005.

[10] R. Young, "Knowledge Management Tools and Techniques Manual," Japan, 2011.

[11] A. Yosua and J. H. Tjakraatmadja, "Assessment and Planning of Knowledge Management at PT Dirgantara Indonesia (Persero)," in Procedia - Social and Behavioral Sciences, 2015, pp. 109124.

[12] Y.-M. Wang and Y.-C. Wang, "Determinants of firms' knowledge management system implementation: An empirical study," Comput. Human Behav., vol. 64, pp. 829-842, 2016. 